\title{
Harwell moves into contract research
}

During the last few years the role of the Atomic Energy
Research Establishment at Harwell has undergone profound
changes, and there have been equally marked changes in the
administration of the laboratory and in the outlook of the staff.

Harwell was originally a one-purpose laboratory - a very large one, it is true, concerned with many scientific disciplines - devoted entirely to atomic energy. The British Government (through its agencies and contractors) was its sole major customer. It now sells applied scientific effort of high quality to any customer with the need to augment his own $R$ \& $D$ capabilities. Research is still confined primarily to the 'hard' sciences of physics, chemistry, metallurgy and engineering and their associated technologies, because it is in these fields that Harwell has its greatest experience and most advanced equipment. There remains, of course, a very substantial concern with atomic energy matters, mainly in reactor materials and their development for the fast reactor programme ; a significant, though diminishing, effort is devoted to underlying research in the nuclear field. However, there has been a rapid growth in the nuclear applications outside atomic energy (for example, industrial radioisotopes) and, more recently and significantly, in work having no direct connection at all with atomic energy (for example, the development of industrial ceramics or the commercial applications of computer technology).

Reactor work and underlying nuclear research are financed by the British Government and by the nuclear industry who are the customers, as are certain non-nuclear tasks such as atmospheric pollution studies which are undertaken for the national benefit. The great bulk of 'non-reactor' work is, however, ordered and paid for on a 'customer/contractor' basis by industrial firms or by other outside organisations ; it may even be done in anticipation of finding a customer later.

It is generally recognised that no organisation has laboratories large enough to meet all its own R \& D needs, and those that might be thought self-sufficient in research are often most aware of the value of outside support. In consequence, problems come to Harwell from every kind and size of industrial concern, from Government and Muni- cipal departments and other research

Most of Harwell's work is undertaken for British organisations but to an increasing extent is providing assistance overseas, particularly in Europe where it is expected that the trend will develop rapidly with the entry of Britain into the Common Market.

The applied work covers a very wide field indeed, as will be seen from Table 1.

It is neither practical nor useful to try to list here all the facilities and techniques at the disposal of Harwell. A much better picture can be given by picking out a few examples and describing briefly some projects that we have completed recently and of interest to readers of Europhysics News. These will be seen to fall broadly into the categories of consultancy, contract $R$ \& $D$, innovative work, and direct services, and to cover many of the fields outlined in Table 1.

\section{One-shot fusion welding}

Careful study by Harwell physicists of the phenomenon of glow discharge electron production has led to the commercial development of an entirely new 'one-shot' electron beam welding technique. Electrons are produced by bombarding a solid metal cathode with ions from a gas plasma, the beam shape being primarily determined by the cathode design. Further focusing can be achieved by magnetic lenses, if required, and a high density of electrons can be concentrated at a selected weld spot, or simultaneously along a weld line, in a fully automatic repetitive operation at a rapid cycling rate. Only "rough" vacuum conditions (0.1-0.3 T) are required. Fully engineered welding machines for rapid massproduction of butt welds, or for general purpose welding and machining of metals or ceramics, are being manufactured and sold under licence from Harwell by a commercial firm.

\section{Modular electronic instrumentation}

Harwell has a very wide experience in the design of instruments for radiation measurement, reactor and chemical plant control, etc., together with extensive development and engilaboratories.

\section{R. M. Longstaff}

neering facilities. In conjunction with industry the laboratory can undertake to develop, from outline specifications to fully tested prototypes, instruments and control systems tailored to specific industrial requirements. The majority of these instruments are built as assemblies of standardized (but often specially designed) computer-compatible modules, many of them to international CAMAC or NIM standards. A typical example of a recent co-operative development is the Harwell Blood Pressure Analyser. In this instrument the magnetic tape carrying signals representing a 24 -hour blood-pressure and electrocardiogram record may be analysed automatically at 25 times real time by use of the playback deck. The signals may also be fed simultaneously into a UV recorder, and the whole record may be played out either at slow sped to display a 24-hour record on a few feet of paper, or at a fast speed to indicate single cycles of events. The instrument was developed jointly with the Radcliffe Infirmary, Oxford.

\section{X-ray diffraction services}

Harwell employs $\mathrm{x}$-ray diffractometry very extensively for determining the crystallographic structure of solids, particularly nuclear fuels and other reactor materials. The equipment available here is probably as advanced as any in the world, and is being used increasingly for tackling problems brought in by outside clients. In particular, very full use is made of computers for controlling operations and for recording and processing data ; this enables reports to be produced on clients' samples with a rapidity which transforms $\mathrm{x}$-ray diffraction, for the first time, into a potentially routine analytical technique. All the standard $x$-ray diffraction techniques are available with the addition of facilities for goniometric work of the very highest precision.

Many other methods of physical examination of materials in the solid state are available to outside clients, including advanced optical and electron microscopy, and electron and ion beam methods of analysis (LEED, Auger, Esca, etc.). 


\section{Controlled atmosphere \\ electron microscopy}

Many chemical and physico-chemical reactions of great technological importance take place at gas-solid interfaces. To study some of these reactions in detail, Harwell has adapted an electron microscope so that the specimens can be viewed in reactant gases at temperatures up to $1200^{\circ} \mathrm{C}$ and pressures up to $\sim 200 \mathrm{~mm}$. The physical phenomena can be studied, both in real time and played back from a videotape record at any desired speed. Reactions that have already been studied, with valuable results, include metal-catalysed oxidation of graphite, and the formation and growth of carbon filaments from the iron-catalysed decomposition of acetylene. Considerable industrial interest has been expressed, particularly where catalysts and problems of catalyst-poisoning are concerned.

\section{A new non-dispersive $x$-ray fluorescence analyser}

Harwell has developed a new type of non-dispersive $\mathrm{x}$-ray fluorescence analyser which incorporates a small $\mathrm{x}$-ray tube generating characteristic $x$-rays of high purity. The analyser approaches the compactness and low cost of the portable radioisotope analysers, while it shows the high sensitivity and good discrimination over the full range of useful elements ( $A$ to $U$ ) possessed by the much larger and more expensive $\mathrm{x}$-ray tube analysers using crystal diffraction for energy selection.

\section{Heat transfer and fluid flow}

The importance to many industries of solving problems in heat transfer and fluid dynamics has led to the formation at Harwell, in association with other laboratories of the United Kingdom Atomic Energy Authority, of an international subscription and information service in heat transfer and fluid flow, backed by extensive experimental facilities. Data are provided (usually in a readily usable computerised form) for application to the client's design and operational problems, especially in the power-plant, petrochemical, cryogenic and engineering industries. A limited number of design reports are prepared and circulated each year on problems selected jointly by the subscribers, and a monthly information digest is circulated. Subscribers are entitled to a limited amount of private consultancy without additional charge. The service at present has about 50 subscribers from 5 different countries, some of them being multinational companies.

\section{Table 1 Principal activities at Harwell}

Materials technology and science

Development of ceramics, carbon and other fibres, cermets, metals, glasses, plastics, composites, coatings. Fabrication and production techniques. Studies of properties and applications of materials.

Quality control, analysis testing, measurement

Development of chemical and physical methods of analysis. Nondestructive testing. Testing and characterization of materials of all kinds. Optical, electron and ion microscopy. In-situ measurements. Calibration of instruments.

\section{Development of electronics and instrumentation}

Nuclear and radiation measuring instruments. Portable instruments for environmental monitoring and mineral prospecting, etc. On-line instrumentation. Modular systems. Semiconductor development.

\section{Chemical engineering and process technology}

Heat transfer and fluid flow studies. High temperature technology. Desalination and water treatment. Plant kinetics investigations. Design and optimization of chemical plant. Waste management.

\section{Computer technology and applications}

Systems analysis and design. Optimization programmes. Multi-access technology. Computer interfacing. Software engineering. Process control. Workshop scheduling. Information retrieval. Pattern recognition.

\section{The environment and its resources}

Treatment of hazardous wastes. Pollution studies. Development of instruments for mining and quarrying. Investigation of coastal sediment movements. Hydrological studies. Environmental studies. Design of special buildings.

\section{Nuclear services}

Reactor and accelerator irradiations. Post-irradiation examinations. 'Hot' laboratory facilities. Transport, storage and disposal of radioactive materials.

\section{Nuclear irradiations and post-irradiation examinations}

Harwell, with the other establishments of the UKAEA and in association with the British nuclear industry, can make available to clients throughout the world a very large range of facilities for the development and proving of nuclear fuels and reactor materials. The nuclear facilities available at Harwell for use on commercial terms include the Variable Energy Cyclotron, two $23 \mathrm{MW}$ high-flux materials testing reactors, a very wide range of ion and electron accelerators (including a $1 \mathrm{MW}$ electron microscope which can also be used for studying radiation damage while it is actually taking place), and extensive post-irradiation and radiochemical laboratories.

An enormous range of work is undertaken for clients in the nuclear industries, in universities and research establishments (including biomedical research) and in a very wide field of general industry. A recent example of industrial work involved the irradiation of the cylinder liner of an internal combustion engine with accelerated protons, and of a set of piston rings with neutrons in a reactor. The assembled engine was used for testing oil additives by analysing the detritus in the oil radiometrically for ${ }^{56} \mathrm{Co}$ from the rings and ${ }^{55} \mathrm{Fe}$ and ${ }^{59} \mathrm{Fe}$ from the liner simultaneously. Another current example is the routine use of neutron radiography as an industrial nondestructive testing technique complementary to $\mathrm{x}$ - and gamma-radiography.

\section{Enthusiastic staff}

The changes described here are not only in the nature and organisation of the work done at Harwell, but much more profoundly in the outlook of the people doing it, particularly the scientific staff. The pressures of the marketplace have, on the whole, been accepted by Harwell's scientists not as a tiresome constraint on their freedom of research, but as an additional challenge to be met with the same enthusiasm that in earlier years enabled Harwell to achieve such signal success in atomic energy research. The results are speaking for themselves as more and more firms accept the invitation to "have a word with Harwell". 